Bartın University Journal of Faculty of Economics and Administrative Sciences, 2021, Volume 12, Issue 24

\title{
TR81 Bölgesinin Yenilenebilir Enerji Durumu
}

\author{
Doç. Dr. Ahmet KAMACI \\ Bartın Üniversitesi, İktisadi ve İdari Bilimler Fakültesi, İktisat Bölümü \\ akamaci@bartin.edu.tr, OrcID: 0000-0002-7858-6131
}

\section{Doç. Dr. Yaşar AKÇA}

Bartın Üniversitesi, İktisadi ve İdari Bilimler Fakültesi, İşletme Bölümü

yakca@bartin.edu.tr, OrcID: 0000-0001-6207-0387

\section{$\ddot{O} \mathbf{z}$}

Sürdürülebilir bir yaşam kalitesi sağlayabilmek için sürdürülebilir bir enerji üretim sistemi kaynaklarının oluşturulması gerekmektedir. Geleneksel enerji kaynaklarını oluşturan petrol, doğalgaz ve kömürün kullanımı sonucunda çevreye olan zararları gün geçtikçe artmaktadır. Ülkeler bugün fosil yakıtların alternatifini oluşturan yenilenebilir enerji kaynaklarına yönelmiş̧lerdir. Bu çalışmanın amacı TR81 bölgesinin (Bartın, Karabük, Zonguldak) yenilenebilir enerji kaynaklarının biyokütle, güneş enerjisi, hidrolik, jeotermal enerji ve rüzgâr enerjisi olmak üzere beş kategoride durumunun incelenmesidir. Çalışma kapsamında öncelikle konu ile ilgili literatür taranmıştır. Bölgenin yenilenebilir enerji türleri açısından gösterge rakamları ortaya konulmuştur. Sonuç kısmında bölgenin yenilenebilir enerji kaynaklarında mevcut durum tespit edilmiştir. Gerek yerli ve gerekse yabancı özel sektör enerji yatırımcıları ile kamu sektörü için yenilenebilir enerji yatırımlarında yol haritası oluşturulmuştur.

Anahtar Kelimeler: Biyokütle, Güneş Enerjisi, Hidrolik, Jeotermal Enerji, Rüzgâr Enerjisi

JEL Sınıflandırmaları: Q41, Q42. 


\title{
Renewable Energy Status of TR81 Region
}

\begin{abstract}
To ensure a sustainable quality of life, sustainable energy production system sources need to be established. As a result of the use of oil, natural gas and coal, which make up traditional energy sources, their damage to the environment beings is increasing day by day. Countries today have turned to renewable energy sources which are an alternative to fossil fuels. The aim of this study is to scrutinize the state of renewable energy sources in the TR81 region (Bartın, Karabük, Zonguldak) in five categories: biomass, solar energy, hydraulics, geothermal energy and wind energy. In this context, literature on the subject was searched first. Indicative figures were put forward in terms of the renewable energy types of the region. In the conclusion section, the current situation of the region in renewable energy sources is determined. A roadmap for renewable energy investments was established for both domestic and foreign private-sector energy investors and the public sector.
\end{abstract}

Keywords: Biomass, Solar Energy, Hydro Energy, Geothermal Energy, Wind Energy.

JEL Classification: Q41, Q42.

\section{Giriş}

Enerji, hayatın olmazsa olmaz temel bileşenlerinden biridir. Her ülkenin ekonomik yönden kalkınmasında, sanayileşmesinde ve refahın sağlanmasında gereklidir. Bütün endüstriler enerjiye ihtiyaç duymakta ve sahip oldukları enerji sayesinde faaliyetlerini sürdürmektedirler. Ayrıca artan nüfus, köyden kente göçle birlikte yoğun şehirleşme, teknolojik gelişmeler, yeni makine ve cihazların kullanımı enerjiye olan ihtiyacı körüklemektedir. Türkiye'nin cari işlemleri içinde yer alan ithalat rakamının büyük bir kısmını enerji ve türevleri meydana getirmektedir. Ülke çapında ihtiyaç duyulan enerji talebi özellikle ithalat yoluyla karşılanmaktadır. Enerjide dişa bağımlılık, hem kur riskini hem de muhtemel yaşanabilecek enerji darboğazlarına karşı ekonomiyi koruması hale getirmektedir.

Enerji kaynakları iki türden meydana gelmektedir. Bunlar; yenilenemez enerji kaynakları ve yenilenebilir enerji kaynaklarıdır. Kullanıldığında tükenen enerji kaynaklarına yenilenemez enerji kaynakları denir. Bu yenilenemez enerji kaynakları; petrol, doğalgaz ve kömürden oluşur (Yağl, Koç, Koç, Görgülü ve Tandıroğlu, 2016). Yenilenemez enerji kaynakları sonlu olduğundan kullanıldığında hem tükenmekte hem de içeriğinde yer alan maddeler dolayısıyla çevreye zarar vermektedir.

Diğer taraftan tüketilmesine rağmen hiçbir zaman azalmayan, doğal olarak kendiliğinden yenilenen, temiz ve güvenli enerji kaynakları da bulunmaktadır. Bu tür 
enerji kaynaklarına yenilenebilir enerji denilmektedir. Özellikle hidrolik, güneş, rüzgâr, jeotermal ve biyokütle enerjileri yenilenebilir enerji kaynaklarını temsil etmektedir. Dünya ülkelerinin sahip oldukları potansiyel yenilenebilir enerji kaynaklarını harekete geçirme ve kullanma trendleri yıllar itibariyle artmktadır (Ürün ve Soyu, 2016:32).

\section{Yenilenebilir Enerji Kaynakları}

Yenilenebilir enerji kaynakları, yenilenemez enerji kaynaklarına göre daha çevrecidir. Hiçbir zaman tükenmeyen ve sürekli kendini yenileyen kaynaklardır. Bu kaynaklar, güneş, rüzgâr, hidrolik, biyokütle ve jeotermal enerjiden oluşmaktadır (Kaya, Şenel ve Koç, 2018:219). Ayrıca dalga-gelgitleri ve hidrojen diğer yenilenebilir enerji kaynakları arasında yer almaktadır. Güneş enerjisinin kaynağı güneştir. Rüzgâr enerjisinin kaynağı rüzgârdır. Hidrolik enerjinin kaynağı nehirler ve akarsulardır. Biyokütle enerjisi biyolojik atıklardan elde edilirken; jeotermal enerji yeraltı sularından elde edilmektedir. Dalga gelgit enerjisi ise okyanus ve denizlerden elde edilmektedir. Hidrojen enerjisi, su ve hidroksitlerden elde edilmektedir.

\subsection{Güneş Enerjisi}

Dünyanın yenilenebilir enerji kaynaklarından en önemlisi güneştir. Güneş enerjisi, tüm enerji akışlarını etkilemektedir. Hem 1sıveren hem bu 1sıyı elektriğe çeviren bir kaynaktır (Varınca ve Gönüllü, 2006:271). Güneş enerjisini 1sı ve elektriğe dönüştüren temel araçlar; güneş kolektörleri, güneş pilleri ve güneş santralleridir (Kaya ve Koç, 2015:41). Güneş enerjisinden 1sıtma ve elektrik elde etmekte yararlanılmaktadır. Güneş enerjisi çevreci, temiz ve güvenli bir enerji kaynağı olduğu için fosil enerji kaynaklarına alternatiftir. Türkiye'nin güneş potansiyeli coğrafi konumdan kaynaklı olarak oldukça iyi durumdadır.

\subsection{Rüzgâr Enerjisi}

Rüzgâr gücü, dünyada kullanımı en çok artan yenilenebilir enerji kaynağıdır (Ata ve Öcal, 2014:3). Güneş, dünya atmosferini ve yeryüzü coğrafyasını farklı derecelerde 1sıtmaktadır. Isınan hava atmosfere doğru yükselir. Isınan havanın yerini soğuk hava doldurarak rüzgâr ortaya çıkmaktadır. Ayrıca yeryüzünün sahip olduğu sıcaklık, nem ve basınç farklılıkları da hava hareketlerine yol açar. Rüzgâr, atmosferde bolca bulunur. Her ne kadar enerjiyi üreten rüzgâr türbinlerinin kurulum maliyeti yüksek (Bağc1, 2019:108) olsa da kısa sürede faaliyete geçirilmektedir. Rüzgâr türbinleriyle kinetik enerji elektrik enerjisine dönüşür (Şenel ve Koç, 2015:47). Türbinler, 30 yıl gibi uzun bir süre kullanıldığından kurulum maliyetleri yıllar itibariyle düşer. Rüzgâr enerjisinin dezavantajları da vardır. Örneğin rüzgârın hızı değişken olduğundan her yere rüzgâr santrali kurulamaz. Bu sebeple rüzgâr enerjisi bölgeye özgü yenilenebilir enerji kaynağıdır ve çok fazla tercih edilmektedir (Özen, Şaşmaz ve Bahtiyar, 2015:88; Y1lmaz ve Öziç, 2018:530).

\subsection{Hidroelektrik Enerji}


Akarsulardan elde edilmektedir. Hidrolik enerji, suyun barajdan düşmesiyle ortaya çıkmaktadır. Dünyada en yaygın kullanılan yenilenebilir enerji kaynağıdır. Su kıtlığ ve kuraklık gibi sorunlar hidrolik enerji üretimini negatif etkilemektedir. Bakım giderleri düşüktür. Temiz çevre bakımından oldukça önemli bir yere sahiptir (Karagöl ve Kavaz, 2017:13). Özellikle nehir yataklarında kurulan barajlar sayesinde su tutulmakta ve bu sudan elektrik üretimi gerçekleştirilmektedir (Koç ve Şenel, 2013:37).

\subsection{Biyokütle Enerji}

Fosil olmamış bitkisel ve hayvansal maddelerden, evsel ve sanayi atıklarından elde edilen yenilenebilir enerji kaynağıdır. Biyokütle enerjisi, yakıt olarak kullanıldığından dolayı biyoyakıt olarak da anılmaktadır (İlleez, 2020:317). Biyokütle enerjisi, çevre kirliliğine neden olmaz. Mevcut çevre kirliliğinin azaltılmasında faydalıdır (Bağcı, 2019:109). Biyokütlenin üretiminde \%64 odun atıkları, \%24 kentsel katı atıklar, \%5 tarımsal atıklar ve $\% 5$ atık gazlar kullanılmaktadır (Önal ve Yarbay, 2010:88).

\subsection{Jeotermal Enerji}

Elektrik üretiminde, 1sıtma amaçlı olarak, sıcak su temininde, termal turizm ve sanayi faaliyetlerinde kullanılmaktadır. Jeotermal enerji, yerkabuğunun derinliklerindeki sıcak kuru kayaların içerdiği su, buhar veya gaz formundaki termal bir enerjidir (Kaya ve Koç, 2015:41). Sicak su ve buhar sonucunda elde edilmektedir. AlpHimalaya sistemi içinde bulunan Türkiye aktif faylar bakımından oldukça zengindir. Bu fay hatları boyunca oldukça fazla doğal sıcak su akışı mevcuttur (Yılmaz, 2012:43). Jeotermal enerji şeker üretiminden tuz üretimine, konservecilik, mantar yetiştiriciliği, balık kurutma, sera, kümes ve havuz ısıtmasına kadar birçok alanda kullanılmaktadır.

\subsection{Diğer Yenilenebilir Enerjiler}

Yenilenebilir enerji kaynakları olarak yukarıda söz konusu edilen 5 kaynak gösterilse de dalga gel-git ve hidrojen enerjisi diğer yenilenebilir enerjilerdir. Dalga gelgit enerjisi, yüksek enlemlere sahip bölgelerde rüzgârların sayesinde deniz yüzeyinde oluşan dalgalardan elde edilmektedir (Akova, 2008:190). Tükenmez bir enerji kaynağ1 olan dalga gel-git enerjisinin bazı olumsuz yanları da vardır. Bunlar; günün belli zamanlarında elde edilmesi ve sadece belli bölgelerde oluşmasıdır (Çukurçayır ve Sağır, 2008:268).

Ele alınacak son yenilenebilir enerji kaynağı hidrojen enerjisidir. Karbon içermediğinden çevre kirliliği problemlerine yol açmayan hidrojen, aslında doğal bir enerji kaynağı değildir. Birincil enerji kaynaklarından üretilerek kullanılır. Maliyeti fazla olsa da bu maliyetin zaman içinde düşeceği ve yakın gelecekte daha fazla kullanılacağı öngörülmektedir (Kumbur, Özer, Özsoy ve Avc1, 2005). 


\section{Dünyada Yenilenebilir Enerjinin Durumu}

Yenilenebilir enerji kaynakları daha çevreci olsa da yenilenemez enerji kaynakları çok daha fazla kullanılmaktadır. Ancak bu kaynakların kullanıma bağlı olarak azalması nedeniyle ülkeler yenilenebilir enerji kaynaklarına yönelmekte ve her geçen gün daha fazla yenilenebilir enerjiyi kullanmaktadır. Grafik 1'de 2018 yılında dünya enerji arzının görünümü verilmiştir.

\section{Grafik 1: Dünya Enerji Arzı (2018)}

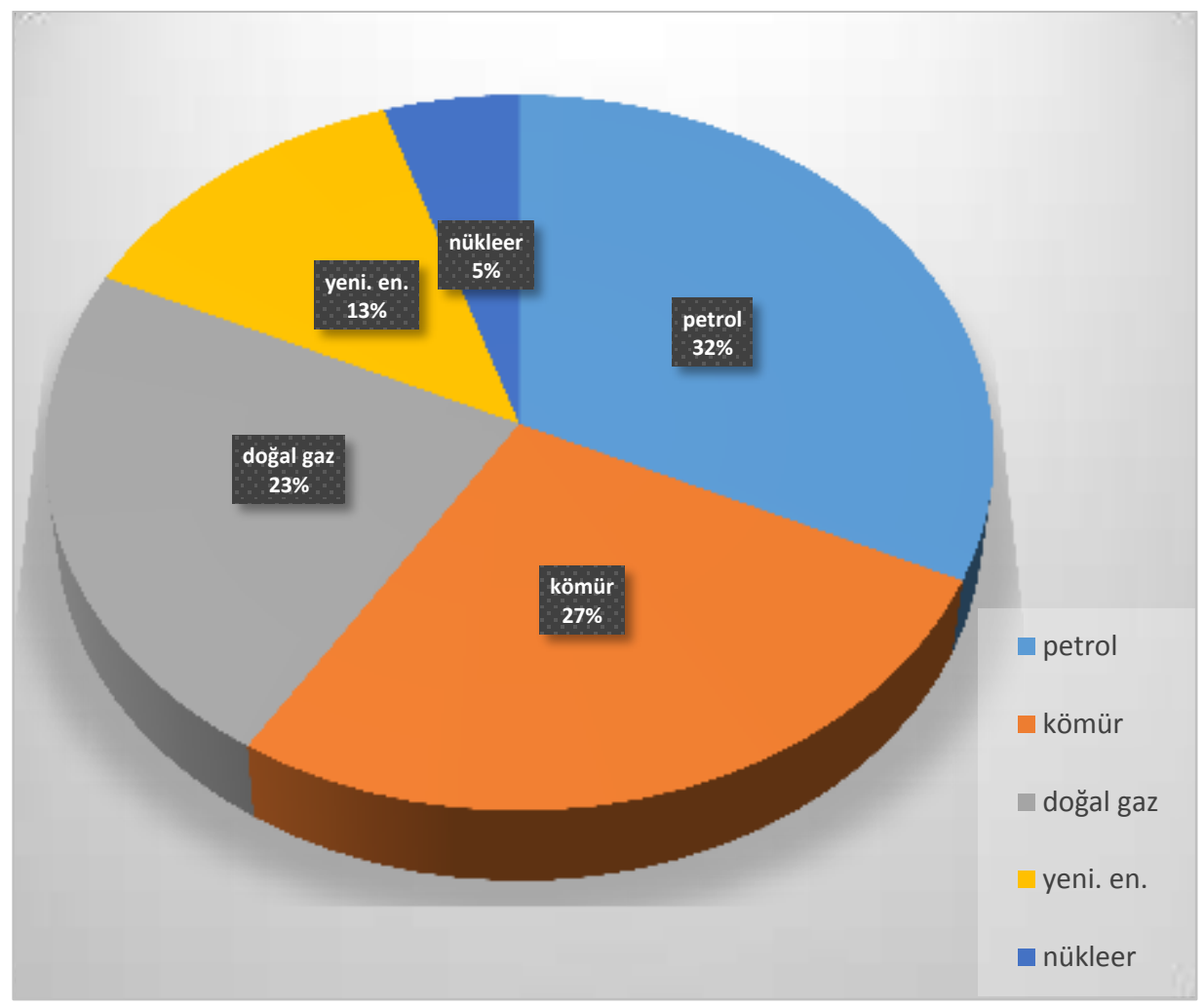

Kaynak: www.iea.org

Grafik 1'de görüldüğü üzere, 2018 yılında dünyada yenilenemez enerji kaynaklarının toplam enerji arzı içindeki payı \%87 iken; yenilenebilir enerjinin payı sadece \%13'tür. Yenilenemez enerji arzında ilk sırayı petrol almakta ve petrolü kömür ve doğalgaz takip etmektedir. 
Tablo 1'de ise, 2018 yılındaki toplam enerji arzında dünyada ilk 10 ülke verilmiştir.

Tablo 1: Toplam Enerji Arzında İlk 10 Ülke (2018)

\begin{tabular}{|l|l|l|c|}
\hline Ülke & \multicolumn{1}{|c|}{ Aoplam Enerji } & Dünya Pay1 \\
& \multicolumn{1}{|c|}{ Arz1 (Mtoe) } & $2018)$ \\
\hline Çin & 3196 & & $15.6 \%$ \\
\hline ABD & 2231 & & $6.4 \%$ \\
\hline Hindistan & 919 & & $5.3 \%$ \\
\hline Rusya & 759 & & $3 \%$ \\
\hline Japonya & 426 & & $2.1 \%$ \\
\hline Almanya & 302 & & $2.1 \%$ \\
\hline Kanada & 298 & & $2.0 \%$ \\
\hline Brezilya & 287 & & $2.0 \%$ \\
\hline Kore & 282 & & $100 \%$ \\
\hline İran & 266 & & \\
\hline DÜNYA & 14282 & & \\
\hline
\end{tabular}

Kaynak: iea.org

Tablo 1'e göre, dünyada toplam enerji arzında \%22,4'lük pay ile Çin ilk sıradadır. Çin'i \%15,6'lık pay ile ABD, \%6,4'lük pay ile Hindistan ve \%5,3'lük pay ile Rusya takip etmektedir. Diğer bir deyişle ilk 4 ülke dünyadaki toplam enerjinin yarısını üretmektedir. Türkiye ise 144,2 Mtoe (milyon ton eşdeğer petrol) ile 18. sıradadır ve dünyadaki enerji arzının \%1'inden daha fazlasını üretmektedir. Ancak Grafik 1'de görüldüğü üzere bu enerji arzının büyük çoğunluğu yenilenemez enerjidir ve Tablo 1 'deki rakamlar yakın gelecekte değişebilecektir. 
Tablo 2'de ülkelerin yenilenebilir enerji kapasiteleri verilmiştir.

Tablo 2: Toplam Yenilenebilir Enerji Kapasitesi

\begin{tabular}{|c|c|}
\hline Ülke & 2017 (MW) \\
\hline DÜNYA & 2179099 \\
\hline Afrika & 42139 \\
\hline Etiyopya & 4301 \\
\hline G. Afrika & 4959 \\
\hline ASYA & 918655 \\
\hline Çin & 618803 \\
\hline Hindistan & 106282 \\
\hline AVRASYA & 96326 \\
\hline Rusya & 51779 \\
\hline Türkiye & 38725 \\
\hline AVRUPA & 512348 \\
\hline Almanya & 113058 \\
\hline İspanya & 47989 \\
\hline AB-28 & 445496 \\
\hline Kuzey Amerika & 347635 \\
\hline $\mathrm{ABD}$ & 229913 \\
\hline Güney Amerika & 202120 \\
\hline Brezilya & 128293 \\
\hline
\end{tabular}

Kaynak: IRENA, 2018:2-5. 
Tablo 2'ye göre, dünyada yenilenebilir enerji kapasitesinde en büyük kıta \%42 ile Asya'dır ve bu kıtadaki Çin, \%28 ile tek başına yenilenebilir enerji kapasitesine sahiptir. ABD'nin payı \%10,5; Brezilya'nın payı \%5,88 ve Almanya'nın payı da $\% 5,18$ 'dir. Türkiye ise 38725 MW (megawatt) ile dünyada \%1,77'lik paya sahiptir. Tablo ve grafiklerden yola çıkarak Türkiye'nin hem dünya enerji arzında hem de yenilenebilir enerji potansiyelinde dünyada öncü bir ülke olmadığı ortaya çıkmaktadır. Genel olarak bakıldığında, Türkiye, dünyada \%1'den daha fazla bir paya sahiptir. verilmiştir.

Tablo 3’te güneş, rüzgâr ve jeotermal enerjinin dünya ülkelerindeki görünümü

Tablo 3: Güneş, Rüzgâr ve Jeotermal Enerji Kurulu Gücü (MW)

\begin{tabular}{|l|l|l|}
\hline \multicolumn{1}{|c|}{$\begin{array}{c}\text { Güneş Enerji Santrali } \\
\text { Kurulu Gücü }\end{array}$} & \multicolumn{1}{|c|}{$\begin{array}{c}\text { Rüzgâr Santrali } \\
\text { Kurulu Gücü }\end{array}$} & Jeotermal Enerji \\
\hline Çin (204700) & Çin (187730) & ABD (3676) \\
\hline ABD (75900) & ABD (88927) & Endonezya (2133) \\
\hline Japonya (49000) & Almanya (59240) & Filipinler (1918) \\
\hline Türkiye (6181) & Türkiye (7010) & Türkiye (1579) \\
\hline DÜNYA (509668) & DÜNYA (536536) & DÜNYA (15275) \\
\hline
\end{tabular}

Kaynak: www.enerjiatlasi.com

Tablo 3'de bazı yenilenebilir enerji kaynaklarının dünyadaki dağılımı verilmiştir. Buna göre Çin, dünyadaki güneş enerji santrallerinin \%40’ına; ABD $\% 15$ 'ine sahiptir. Türkiye'nin payı ise $\% 1,2$ 'dir. Kişi başına güneş enerji santrali kurulu gücünde Almanya ilk sırada ve Hollanda ikinci sırada yer almaktadır. Türkiye ise 27.siradadir.

Rüzgâr santrali kurulu gücünde yine Çin (\%35) ve ABD $(\% 16,5)$ ilk iki sırayı paylaşmaktadır. Türkiye, \%1,3'lük pay ile dünya ülkeleri arasında 11.sıradadır. Kişi başına düşen rüzgâr santrali kurulu gücünde Danimarka ilk sıradadır. Türkiye 31.sırada yer bulmaktadir.

Son olarak jeotermal enerjide ABD \%24 ile ilk sırada yer alırken; Endonezya \%14'lük pay ile ikinci sıradadır. Türkiye ise \%10'luk pay ile jeotermal enerji kurulu gücünde dünyada 4.sıradadır. Türkiye'nin yarısı kadar jeotermal enerji kurulu gücü 
bulunan İzlanda ise, kişi başı jeotermal enerji kurulu gücü açısından büyük farkla ilk siradadır.

\section{Literatür Taraması}

Yapılan literatür taramasında Karacadağ Kalkınma Ajansı (2010) tarafından, TRC2 (Diyarbakır ve Şanlıurfa) bölgesinin yenilenebilir enerji potansiyeli incelenmiştir. Çalışmanın sonucunda, Diyarbakır ve Şanlıurfa'nın çok fazla yenilenebilir enerji potansiyeli olmasına rağmen, mevcut potansiyelinin altında olduğu belirtilmektedir. Ayrıca bölgenin Türkiye'de önemli güneş enerji potansiyeline sahip olduğu, biyokütle enerjisinde öncü olabileceği ve rüzgâr ile jeotermal enerji açısından da iyi durumda olduğu, ancak potansiyelin yeterince kullanılmadığına işaret edilmiştir.

Çukurova Kalkınma Ajansı (2012) tarafindan yapılan çalışmada, TR62 bölgesinin yenilenebilir enerji potansiyeli incelenmiştir. Çalışmada Mersin'in Gülnar, Mut ve Silifke ilçelerinde önemli düzeyde rüzgâr enerji potansiyeli olduğu, ayrıca Mersin ve Çukurova bölgesinde güneş enerji potansiyelinin oldukça fazla olduğu belirtilmiştir. Bölgede enerji verimliliğinin arttırılması için hibrit sistemlerin kullanılması gerektiğine dikkat çekilmiştir. Benzer bir çalışma da Zafer Kalkınma Ajans1 (2012) tarafından, TR33 bölgesinin yenilenebilir enerji potansiyeli incelenmiştir. Çalışmanın sonucunda bölgenin önemli bir rüzgâr enerjisi potansiyeline sahip olduğu tespit edilmiştir. Ayrıca bu bölgenin 1500 metreden daha çok rakımlı ve \%20'den daha çok eğimli yerlerinde aşırı rüzgâr gücü barındırdığından, enerji yatırımlarına uygun olmadığı sonucuna varılmıştır. Eroğlu ve arkadaşları (2018) tarafından TR83 bölgesinin yenilenebilir enerji potansiyeli ortaya konulmuştur. Samsun'un bölge illerine göre yeterli olmasa da yenilenebilir enerji potansiyelini daha iyi kullandığı, diğer komşu illerin ise enerji yatırımı eksikliğinden dolayı mevcut potansiyellerini değerlendiremediklerine işaret edilmiştir. Güneş enerjisi için Tokat; hidrolik enerji için Samsun, rüzgâr enerjisi için Tokat, Amasya ve Çorum'un elverişli olduğu, yatırım yapıldığı takdirde önemli bir yenilenebilir enerji potansiyelinin harekete geçirileceğine işaret edilmiştir.

\section{TR81 Bölgesinin Yenilenebilir Enerji Potansiyeli}

BAKKA (2013) tarafından TR81 bölgesi için hazırlanan raporda, Bartın, Karabük ve Zonguldak illerinin yenilenebilir enerji potansiyelleri incelenmiştir. Çalışmada, bölgenin rüzgâr potansiyeli yeterli olmadığından rüzgâr enerji tesislerinin kurulması mümkün değildir sonucuna ulaşılmıştır. Ancak Bartın'ın ilçesi Amasra'nın elverişli bir rüzgâr enerjisi potansiyeline sahip olduğuna dikkat çekilmiştir. 2021 yılı itibariyle sadece Zonguldak'ta 5,22 MW gücünde rüzgâr elektrik santrali faaliyettedir (https://www.enerjiatlasi.com/ruzgar/). Türkiye'de faaliyette bulunan 269 santralin toplam rüzgâr enerji potansiyeli 9559 MW'tır ve TR81 bölgesi yaklaşık 0,005'lik payiyla oldukça yetersizdir. 
Hidroelektrik enerji açısından; Bartın, Zonguldak ve Karabük'ün hidroelektrik enerji potansiyeli yüksektir. Karabük'te $35 \mathrm{MW}, 21 \mathrm{MW}$ ve $14 \mathrm{MW}$ gücünde üç tane, Zonguldak İlinde 33, 11 ve 1,34 MW güçlerinde üç hidroelektrik santrali devrededir. Bartın'da ise 7,92 MWlık Kirazlıköprü baraj1, 20 MW gücünde Kayadibi hidroelektrik santrali ve 6,85 MW gücünde Başak hidroelektrik santrali bulunmaktadır (https://www.enerjiatlasi.com/hidroelektrik/). Bölgenin envanterinde önemli bir potansiyel içeren hidroelektrik santrallerinin tamamı henüz hayata geçirilememiştir.

Güneş enerjisi açısından TR81 bölgesi oldukça zayıftır. 2021 yılı itibariyle Zonguldak ilinde güneş enerjisi santrali üretim lisansına sahip 1 MW kurulu güç ile birlikte çeşitli firmalara ait lisanssız üretim yapan 1,79 MWlık güneş elektrik santralleri kullanımdadır. Ayrıca Karabük'te Enerjisa'ya ait $7 \mathrm{MW}$ kurulu gücü bulunan güneş enerji santrali ve çeşitli firmalara ait lisanssız olarak faaliyet gösteren 5,15 MW güneş elektrik santralleri mevcuttur (https://www.enerjiatlasi.com/gunes/). Bartın'da ise İl Özel İdaresi'ne ait 0,25 MW güneş enerji tesisi bulunmaktadır ve bundan başka güneş elektrik santrali mevcut değildir. Türkiye'de kayıtlı 667 güneş enerji santralinden 6'sı TR81 bölgesinde yer almaktadır. Türkiye'de kurulu olan 7170MW kurulu gücün 14,86 MWlık kısmı, diğer bir deyişle \%002'si TR81 bölgesinde yer almaktadır.

Jeotermal enerji açısından TR81 bölgesinde faaliyette olan bir kuruluş bulunmamaktadır.

TR81 bölgesi, biyokütle enerjisi açısından elverişlidir. Fakat söz konusu yenilenebilir enerji kaynağının ihmal edildiği BAKKA'nın (2013) raporunda ortaya konulmuştur. 2021 yılı itibariyle Bartın, Karabük ve Zonguldak illerini kapsayan TR81 Bölgesinde Biyogaz, Biyokütle, Atık Isı ve Pirolitik Yağ Enerji Santralleri yoktur.

\section{Sonuç}

2000'li yıllardan itibaren gündeme gelen iklim değişikliği ve küresel 1sınmadaki sürekli artışlar dünya çapında yenilenebilir enerji kaynaklarını gündeme çıkarmıştır. Dünya çapında tüm ülkeler, enerji ihtiyaçlarının karşılanmasında yenilenebilir enerjiye daha fazla önem vermeye başlamışlardır. Diğer taraftan yenilenebilir enerji kaynakları aynı zamanda yerli enerji üretimini de ifade etmektedir. Yerli kaynakları oluşturan yenilenebilir enerji kaynaklarının kullanımı sayesinde istihdam artmakta, cari açığa yol açan enerji ithalat tutarları azalmakta ve ülkenin enerji bağımlılığı minimum seviyelere çekilmektedir. Diğer taraftan da enerji kaynaklarında çeşitlilik meydana gelmektedir.

Bu çalışmada TR81 bölgesinin yenilenebilir enerji kaynakları açısından durum tespiti yapılmıştır. Rüzgâr elektrik santrallerinin kurulumu ve işletilmesinde bölge elverişsizdir. Fakat Amasra umut vadetmektedir.

Bölge illerinin sahip olduğu akarsular sayesinde hidroelektrik santralleri, enerji yatırımına elverişlidir ve yatırımcıların ilgisine açıtır. TR81 bölgesi güneş elektrik 
santrali ve jeotermal enerji üretimi açısından yetersizdir. Halen küçük çapta güneş elektrik santralleri faaliyet göstermektedir.

Esas olarak biyokütle enerjisi yatırımlarında TR81 bölgesi büyük bir yenilenebilir enerji yatırım potansiyeline sahiptir. Fakat bu alanda bir yatırım bugüne kadar henüz gerçekleştirilmemiştir. Biyogaz, Biyokütle, Atık Isı ve Pirolitik Yağ Enerji Santrallerini kurup işletecek yatırımcılarını beklemektedir.

\section{Kaynakça}

Akova, İ. (2008). Yenilenebilir enerji kaynakları, İstanbul: Nobel Akademik Yayıncılık

Ata, R. ve Öcal, F. (2014). Manisa'nın yenilenebilir enerji potansiyelinin analizi, C.B. $\ddot{U}$. Fen Bilimleri Dergisi, 10(1), 1-10.

Bağcı, E. (2019). Türkiye'de yenilenebilir enerji potansiyeli, üretimi, tüketimi ve cari işlemler dengesi ilişkisi, Research Studies Anatolia Journal, 2(4), 101-117.

BAKKA (2013). 2014-2023 Batı Karadeniz Bölge Planı Zonguldak, Karabük, Bartın Mevcut Durum Analizi, Cilt:1, Zonguldak. http://bakkakutuphane.org/kategori/bolge-planlari/23 (erişim tarihi 16.06.2021)

Çukurçayır, M.A. ve Sağır, H. (2008). Enerji sorunu, çevre ve alternatif enerji kaynakları, Selçuk Üniversitesi Sosyal Bilimler Enstitüsü Dergisi, 20, 257-278.

Çukurova Kalkınma Ajansı (2012). Çukurova kalkınma ajansı yenilenebilir enerji raporu. Haz. Ceren Topçu ve Dilşad Türtük Yünsel, 2012/03, Adana. http://www.cka.org.tr/dosyalar/enerji.pdf (erişim tarihi 16.06.2021)

Eroğlu, N., Çoban, M.N. ve Kangal, N. (2018). Temiz enerji kapsamında TR83 bölgesinin değerlendirilmesi, Balkan Sosyal Bilimler Dergisi, 7(13), 83-105.

https://www.enerjiatlasi.com/ (erişim tarihi 16.06.2021)

IRENA (2018). Renewable capacity statistics 2018, International Renewable Energy Agency (IRENA), Abu Dabi.

İlleez, B. (2020). Türkiye'de biyokütle enerjisi, Içcinde: Türkiye'nin Enerji Görünümü 2020, TMMOB Makine Mühendisleri Odası Raporu, Yayın No: MMO/717, Ankara.

Karacadağ Kalkınma Ajansı (2010). TRC2 (Diyarbakır-Şanlıurfa) bölgesi yenilenebilir enerji raporu. Editör: Bülent Yeşilata, Diyarbakır. 
Karagöl, E.T. ve Kavaz, İ. (2017). Dünyada ve Türkiye'de yenilenebilir enerji, Seta Analiz, 197, 1-32.

Kaya, K. ve Koç, E. (2015). Enerji kaynakları-yenilenebilir enerji durumu. Mühendis ve Makina, 56(668): 36-47.

Kaya, K., Şenel, M. C. ve Koç, E. (2018). Dünyada ve Türkiye'de yenilenebilir enerji kaynaklarının değerlendirilmesi. Technological Applied Sciences, 13(3), 219234.

Koç, E. ve Şenel, M.C. (2013). Dünyada ve Türkiye'de enerji durumu-genel değerlendirme. Mühendis ve Makina, 54(639), 32-44.

Kumbur, H., Özer, Z., Özsoy, H.D. ve Avc1, E.D. (2005). Türkiye'de geleneksel ve yenilenebilir enerji kaynaklarının potansiyeli, çevresel etkilerinin karşılaştırılması. III. Yenilenebilir Enerji Kaynakları Sempozyumu, Mersin.

Mangır, F., Karaçor, Z., Konya, S. ve Yardımcı, P. (2018). Yenilenebilir enerji tüketimi ile ekonomik büyüme arasındaki ilişki: OECD ülkeleri örneği. Uluslararası Ekonomi Araştırmaları ve Finansal Piyasalar Kongresi, 961-980, Nevşehir.

Önal, E. ve Yarbay, Z. (2010). Türkiye'de yenilenebilir enerji kaynakları potansiyeli ve geleceği. İstanbul Ticaret Üniversitesi Fen Bilimleri Dergisi, 9(18), 77-96.

Özen, A., Şaşmaz, M.Ü. ve Bahtiyar, E. (2015). Türkiye'de yeşil ekonomi açısından yenilenebilir bir enerji kaynağı: rüzgâr enerjisi, KMÜ Sosyal ve Ekonomik Araştırmalar Dergisi, 17(28), 85-93.

Şenel, M.C. ve Koç, E. (2015). Dünyada ve Türkiye'de rüzgâr enerjisi durumu-genel değerlendirme. Mühendis ve Makina, 56(663), 46-56.

Ürün, E. ve Soyu, E. (2016). Türkiye'nin enerji üretiminde yenilenebilir enerji kaynakları üzerine bir değerlendirme. Dumlupınar Üniversitesi Sosyal Bilimler Dergisi, ICEBSS Özel Sayısı, 31-45.

Varınca, K.B. ve Gönüllü, M.T. (2006). Türkiye'de güneş enerjisi potansiyeli ve bu potansiyelin kullanım derecesi, yöntemi ve yaygınlığı üzerine bir araştırma, 1. Ulusal Güneş ve Hidrojen Enerjisi Kongresi, Eskişehir.

IEA, International Energy Agency, www.iea.org (Erişim tarihi 16.06.2021)

Yağl1, H., Koç, Y., Koç, A., Görgülü, A. ve Tandiroğlu, A. (2016). Parametric optimization and exergetic analysis comparison of subcritical and supercritical organic Rankine cycle (ORC) for biogas fuelled combined heat and power 
(CHP) engine exhaust gas waste heat. Energy, 111, 923-932. https://doi.org/10.1016/j.energy.2016.05.119

Y1lmaz, M. (2012). Türkiye'nin enerji potansiyeli ve yenilenebilir enerji kaynaklarının elektrik enerjisi üretimi açısından önemi, Ankara Üniversitesi Çevrebilimleri Dergisi, 4(2), 33-54.

Yılmaz, E.A. ve Öziç, H.C. (2018). Türkiye'nin yenilenebilir enerji potansiyeli ve gelecek hedefleri, Ordu Üniversitesi Sosyal Bilimler Araştırmaları Dergisi, 8(3), 525-535.

Zafer Kalkınma Ajansı (2012). TR33 bölgesinin yenilenebilir enerji potansiyeli ve stratejik alt bölgelerin tespiti. Proje Yürütücüsü: F. Çelebioğlu, Proje No: ZAFER/2012-01/MD-DFD, Kütahya. 